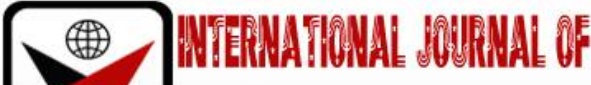

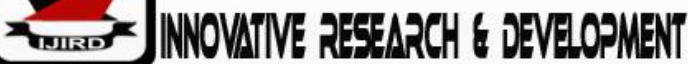

ISSN 2278-0211 (Online)

\section{Delays and Cost Overruns in Construction Projects in Nigeria: Causes and Remedies}

\author{
Gidanmana Philemon Usman \\ Principal Lecturer, Department of Quantity Surveying, \\ College of Environmental Studies, Kaduna Polytechnic, Kaduna, Nigeria
}

\begin{abstract}
:
Despite improvements in the control techniques available for managing construction projects in Nigeria, the projects still do not meet their cost and time objectives. Delays and cost overruns are still prevalent even as time and cost performance remains key criteria for project success. Yet empirical studies conducted on this subject are few. This paper investigates the underlying causes for delays and cost overruns observed on selected construction projects in major Nigerian cities. Quantitative and qualitative methods were used to generate data for the research; structured questionnaire survey was used to obtain information on the causes of delays and cost overruns, and face-to-face interview with respondents actively involved on the selected projects helped to develop mitigating strategies to curb delays and cost overruns. Data generated was analyzed using Mean Scores, weighted averages and Spearman correlation coefficients to arrive at the significant causes of delays and cost overruns. The study found that delays and cost overruns occurred in varying degrees in all the projects studied. The most significant causes of delays and cost overruns are design/scope changes, inadequate availability of skilled resources, ineffective procurement planning, price escalations of construction materials and labour, and scope change. The study developed14 and 15strategies for mitigating delays and cost overruns respectively. These strategies would help to improve time and cost performance on construction projects. Industry practitioners will find them very useful at the planning phase where decisions that define a project are made, and also during project implementation.
\end{abstract}

Keywords: Construction projects, delays, cost overrun, time performance, cost performance, mitigation strategies, project success

\section{Introduction}

Construction projects in Nigeria are infamous owing to the perception of costs exceeding budget and project schedules stretching beyond contract period. This public perception isn't entirely unfounded considering the increasingly large number of construction projects that exceed their contract periods and contract prices. The dearth of comprehensive Nigeria-centric studies on delays and cost overruns in construction projects is a major reason for this research. The huge theoretical and empirical literature available globally on this subject suggests that Nigeria is not immune to the global scourge of time and cost overrun. Instructively, the different literature and studies have shown that the factors responsible for time and cost overrun and their remedies differ from one country to another. This points to the need for local and home-grown experiences and underscores the significance of this study.

This study will, among other things, investigate the major causes of delays and cost overruns observed in Nigeria's construction industry. It is premised on the notion that time and cost overrun could result in project nonperformance and/or failure. Consequently, the study will examine whether time and cost overrun occur in construction projects in Nigeria and whether they affect successful completion of the projects. It will also examine which factors are responsible for time and cost overrun, and the strategies that could help mitigate them in order to deliver successful projects.

\section{Overview of Time and Cost Overruns}

A project lifecycle involves three broad phases, namely: development phase, procurement and construction phase, and operation and maintenance phase. In the development phase, project sponsors estimate the time and cost required to complete the project, after which the contract period is decided and the contract price is agreed upon. More often than not, the completion date turns out different from the set date. This difference between actual period for completion and contract periodis called 'delay' or 'time overrun'. While cost overrun is the difference between actual cost of completion and contract price.

The global literature on time and cost overruns is fairly huge. In their series of interesting empirical research across 20 countries, Flyvbjerg, Holm and Buhl (2002, 2003, and 2004) revealed that $90 \%$ of the 258 projects studied suffered schedule delays and cost overrun in varying proportions. Several other authors have reported similar findings 
with their different explanations on causes. Some authors (Morris and Hough, 1987; Kaming et al.1997; Chan et al.2004 and KPMG-PMI, 2012) found 'imperfect information' and 'technical constraints' as major causes.

A study by Moms and Hough (n.d.) cited in Adam, Josephson and Lindahl (2014) found that 63\% of 1778 construction projects funded by The World Bank exceeded their budgets, and studies by Flyvbjerg $(2005 ; 2007$, p.3) found that project complexity is a significant cause of delays and budget escalations; adding that faulty viability assessment and inaccurate ranking processes promote delays and cost escalations. However, external factors such as delay in receiving statutory approvals, unavailability of critical materials and equipment, inclement weather and poor site conditions are all beyond the control of the different implementing organizations and play unimaginable roles in causing delays and cost overrun (Alghbari et al 2007).

\section{Methodology}

The data for this study was collected in two stages combining quantitative and qualitative methods. In the first stage, quantitative method was deployed using structured questionnaire survey to obtain information on causes of time and cost overruns in construction projects. This approach enhanced understanding of the perception of respondents who were directly involved with the projects selected from major cities across Nigeria for the study. The structured questionnaire survey helped in ascertaining the degree of significance for each of the underlying causes of delay and cost overruns using a 5-point Likert-type scale with these ratings: E.S. (Extremely Significant) rated 5; V.S. (Very Significant) rated 4; M.S. (Moderately Significant) rated 3; S.S. (Slightly Significant) rated 2; and N.S. (Not Significant) rated 1.

The analysis of results adopted a procedure which helped in establishing the mean scores (MS) of the 37 significant causes of delays and cost overruns identified by the study. The score for factors was determined by adding up the scores assigned by the various respondents. Through this, the level of significance of each factor was ascertained. The mean score (MS) for each factor was found using the formula:

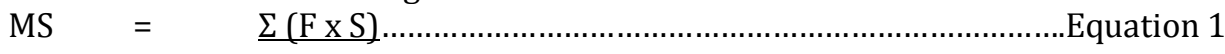

$\mathrm{N}$

Where; $\mathrm{S}$ = score given to each cause of delay or cost overrun by the respondents

$\mathrm{F}=$ frequency of responses to each score for each cause of delay (or cost overrun)

$\mathrm{N}=$ total number of responses received in the respective cause of delay (or cost overrun)

And the weighted average is thereafter calculated using the formula:

Weighted Average $=\mathrm{w}_{\mathrm{a}} \mathrm{x}_{\mathrm{a}}+\mathrm{w}_{\mathrm{b}} \mathrm{x}_{\mathrm{b}}+\mathrm{w}_{\mathrm{c}} \mathrm{x}_{\mathrm{c}}$

Equation 2

Where, $w=$ relative weight (\%); $x=$ mean score; and $a, b \& c$ represent contractor, consultant and client respectively.

The Spearman (rho) rank correlation coefficient was used to measure the differences in ranking between groups of respondents scoring for the different factors (or causes) i.e. clients versus contractors, clients versus consultants, and consultants versus contractors. The ranking for any two groups is calculated thus:

$$
6 \times\left(\sum \mathrm{d}_{\mathrm{i}}^{2}\right)
$$

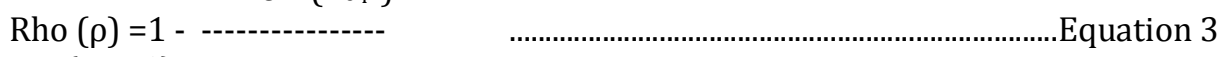

$\mathrm{N} x\left(\mathrm{~N}^{2}-1\right)$

Where, Rho $(\rho)=$ Spearman rank correlation coefficient

$\mathrm{d}_{\mathrm{i}}=$ the difference in ranking between each pair of factors; and $\mathrm{N}=$ number of factors (or variables)

Correlation test was performed to gauge the strength of association between the causes of delay and cost overrun. Since the data collected for this study is nonparametric and ordinal variables, Spearman's correlation was used as a means of examining the relationship between pairs of variables. The correlation coefficient value (or ' $\rho$ ') ranges from -1.0 to +1.0 . The closer $\rho$ is to +1 or -1 , the more closely related the two variables are. The closer the value of $\rho$ is to 1 implies that a strong positive linear relationship exists between the two variables, and the closer the value of $\rho$ is to -1 , means there's a strong negative linear relationship between the two variables. The correlation value \pm 1 is considered a perfect correlation, and zero signifies no correlation at all.

In second stage of the research, qualitative method was deployed using face-to-face interviews with industry practitioners who were directly involved with the projects under review. The interview dwelled on the individual experiences of respondents with time and cost overruns and sought to know first-hand what they considered the best strategies for mitigating the negative impact of delays and cost overruns in construction projects. The views of respondents are tabulated in Table 5, while the suggestions proffered by the interviewees for mitigating the negative impact of these causes is given in Table 6.

\section{Data Collection}

A total of 80 questionnaires were distributed among respondents randomly chosen from different project organizations, out of which 72 (90\%) responded. The data was analyzed using Mean Scores (MS), weighted averages and Spearman Rank coefficient to arrive at significant causes of delays and cost overruns.

Respondents involved in the survey have had varying years of experience in construction projects. The demographics of these respondents is summarized in Table 1: 


\begin{tabular}{|c|c|c|c|}
\hline & Frequency & Percentage $(\%)$ & Cumulative $\%$ \\
\hline \multicolumn{4}{|l|}{ Type of Organization } \\
\hline Client & 19 & 26.4 & 26.4 \\
\hline Consultant & 15 & 20.8 & 47.2 \\
\hline Contractor & 38 & 52.8 & 100.0 \\
\hline \multicolumn{4}{|l|}{ Designation of Respondenis } \\
\hline Project Mgr./Resident Engineer & 46 & 63.9 & 63.9 \\
\hline Site Engineer & 16 & 22.2 & 86.1 \\
\hline Office Engineer & 10 & 13.9 & 100.0 \\
\hline \multicolumn{4}{|l|}{ Size of Projects (in Naira) } \\
\hline Below 1 billion & 1 & 5.0 & 5.0 \\
\hline $1-5$ billion & 9 & 45.0 & 50.0 \\
\hline 5 - 10 billion & 5 & 25.0 & 75.0 \\
\hline Above 10 billion & 5 & 25.0 & 100.0 \\
\hline \multicolumn{4}{|l|}{ Working Experience } \\
\hline $0-4$ years & 2 & 2.8 & 2.8 \\
\hline $4-8$ years & 8 & 11.1 & 13.9 \\
\hline $8-12$ years & 25 & 34.7 & 48.6 \\
\hline Above 12 years & 37 & 51.4 & 100.0 \\
\hline
\end{tabular}

Table 1: Demographic Characteristics of Respondents and Projects

Majority of respondents (52.8\%) in the survey were from contractor organization, and those from client and consultant organizations were $26.4 \%$ and $20.8 \%$ respectively. More than $50 \%$ of the respondents had more than 12 years' experience on construction projects; and less than $15 \%$ had experience of less than 8 years. Over $60 \%$ of the respondents were of senior cadre holding managerial position or equivalent, and less than $15 \%$ were office engineers or equivalent. And $50 \%$ of the projects surveyed were above N5bn in value.

Tables $2 \& 3$ show a summary of data collected from the questionnaire survey conducted.

\begin{tabular}{|cllc|}
\hline \%age Time Overun & Frequency & Percentage (\%) & Cumulative \% \\
\hline $0 \%$ & 0 & 0.0 & 0.0 \\
$1-25 \%$ & 5 & 25.0 & 25.0 \\
$25-50 \%$ & 9 & 45.0 & 70.0 \\
$50-75 \%$ & 4 & 20.0 & 90.0 \\
Above $75 \%$ & 2 & 10.0 & 100.0 \\
& & & \\
\hline
\end{tabular}

Table 2: Delays on the Projects Surveyed in Percentage (\%)

Results show that no project was completed within the estimated time. A significant number (45\%) of the projects experienced delays of $25-50 \%$ beyond the contract period; while a quarter of the projects experienced delays of between $1-25 \%$. Only about $10 \%$ of the projects experienced delays beyond $75 \%$ of the agreed contract period.

\begin{tabular}{|cccc}
\hline \%age Time Overrun & Frequency & Percertage (\%) & Curiulative \% \\
\hline $1-15 \%$ & 4 & 21.0 & 21.0 \\
$15-25 \%$ & 4 & 21.0 & 42.0 \\
$25-35 \%$ & 6 & 31.6 & 73.6 \\
Above 35\% & 5 & 26.3 & 100.0 \\
\hline
\end{tabular}

Table 3: Cost overrun on Projects Surveyed in Percentage (5)

$42 \%$ of the projects studied experienced cost overrun between $1-25 \%$ of the initial contract price; while $31.6 \%$ of them experienced between $25-35 \%$ cost overrun. And 26.3\% of the projects recorded cost overruns above $35 \%$ of the estimated cost of completion. Interestingly, one of the projects reviewed recorded a $20 \%$ cost saving which was attributed to the turnkey contract entered into by the client who put the contractor in charge of both design and implementation of the project. Not only that, but sufficient funds were put at the disposal of the contractor which made project delivery smooth. 


\section{Discussion of Results}

The main thrust of this research is to investigate and ascertain whether agreement exists or not in the aggregate views expressed by the different respondents on the underlying causes of delays and cost overruns in the construction projects selected for the study.

\subsection{Major Causes of Delays and Cost Overruns}

The study investigated factors that significantly cause delays and cost overrun in projects. From responses obtained from the different respondents, the mean score for each variable (factor) of delay and cost overrun was calculated and weighted averages ascertained. Final ranking of the mean scores led to the following ten (10) most significant causes of delays and cost overruns summarized in Table 4:

\begin{tabular}{|lcc|}
\hline \multicolumn{1}{|c}{ Significant causes of Time Overrun } & Rani & Rang \\
Design and scope change & 4.264 & 1 \\
Inadequate availability of skilled resources & 3.803 & 2 \\
Ineffective procurement planning & 3.778 & 3 \\
Ineffective project monitoring & 3.744 & 4 \\
Ineffective project management & 3.674 & 5 \\
Delay in decision making & 3.666 & 6 \\
Delay in obtaining regulatory approval & 3.516 & 7 \\
Inadequate availability of funds & 3.494 & 8 \\
Coordination problems with project team and vendors & 3.355 & 9 \\
Lack of awareness of modern technology & 3.343 & 10 \\
& & \\
\hline Significant causes of Cost Overrun & $M S i$ & Ranking \\
Price escalations of materials beyond earlier projections & 4.508 & 1 \\
Escalation of labour costs/ineffective use of labour & 4.218 & 2 \\
Scope creep & 4.177 & 3 \\
Increasing costs of project financing due to FX and int. rates & 4.133 & 4 \\
Design changes & 4.077 & 5 \\
Inaccurate estimating and budgeting of project & 3.961 & 6 \\
Insufficient availability of skilled resources & 3.732 & 7 \\
Weak contract administration and mgmt. of claims & 3.487 & 8 \\
Weak procurement planning & 3.435 & 9 \\
Poor choice of technology/equipment & 3.280 & 10 \\
\hline & & \\
\hline
\end{tabular}

Table 4: Significant causes of Time and Cost Overrun on Projects

- Delays: In Table 4,'design and scope change' emerged a dominant factor in construction projects, especially large ones which take off long before final design details are in place. With such projects, design and scope change is common practice among designers who keep changing the scope as more details emerge. This practice impacts project time and cost. The next four factors (inadequate skilled resources, ineffective procurement planning, ineffective project monitoring and ineffective project management) are management-related issues bothering on the competencies of personnel engaged in the projects and how effectively these competencies are deployed to achieve project success. Delays in decision making and obtaining regulatory approvals significantly impact timely delivery of projects.

- Cost overrun: Table 4 revealed 'price escalations' of materials and labour as major cause of cost overrun on projects. Initial estimates are based on current input prices at contract stage. Since input prices tend to rise with time, delays are bound to impact the overall project cost. Worthy of note also is the impact of unstable foreign exchange regime in Nigeria occasioned by the weakened local currency, plus the rising costs of financing projects which combine to significantly raise project costs.

\subsection{Tests for Agreements on Causes of Delays and Cost Overruns}

The test for agreement was based on two main hypotheses, namely:

- The null Hypothesis $\left(\mathrm{H}_{0}\right)$ : There is no agreement in the ranking of causes of delays and cost overruns between two groups of respondents.

- The alternative Hypothesis $\left(\mathrm{H}_{\mathrm{A}}\right)$ : There is agreement in the ranking of causes of delays and cost overruns between two groups of respondents.

With a significance level of $95 \%(P=0.05)$, the calculated values of ' $\rho$ ' for 20 pairs of data in all three group cases given in Table 5 are all greater than the critical value of $\rho=0.3783$, which indicates a very significant correlation between two sets of data in each case. Consequently, the Null hypothesis $\left(\mathrm{H}_{0}\right)$ which says there is no significant agreement between the respondents is rejected. The Alternative hypothesis $\left(\mathrm{H}_{\mathrm{A}}\right)$ which says there is agreement in the ranking of causes of delays between the respondents is accepted as most respondents have same perception about the causes of delay. 


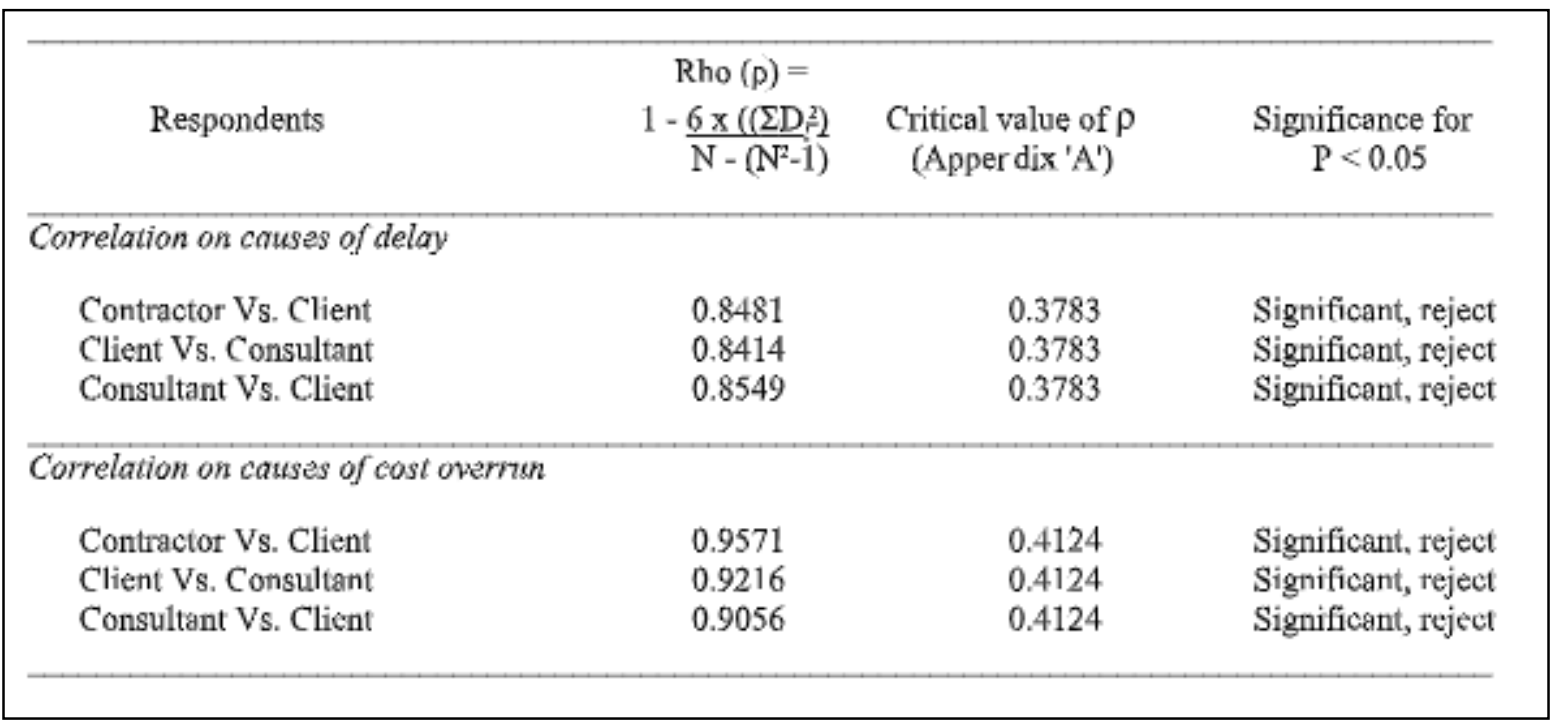

Table 5: Summary of correlation test on ranking on the causes of delays and cost overruns

The second part of Table 5 shows that the calculated values of ' $\rho$ ' for 20 pairs of data in all three group cases are greater than the critical value of $\rho=0.4124$, which indicates a very significant correlation between two sets of data in each case. Consequently, the Null hypothesis $\left(\mathrm{H}_{0}\right)$ which says there is no significant agreement between the respondents is rejected. The Alternative hypothesis $\left(\mathrm{H}_{\mathrm{A}}\right)$ which says there is agreement in the ranking of causes of cost overrun between the respondents is accepted as most respondents have same perception about the causes of cost overrun.

From the analysis of data, the author concluded that there was agreement in the perception of contractor, client and consultant on the factors influencing delays and cost overruns.

\section{Mitigation Strategies}

\subsection{Mitigation Strategies Required to Avoid Time and Cost Overrun}

Face-to-face interview was conducted with respondents randomly selected from client, consultant and contractor organizations. Their experiences and opinions provided great insight for this study. The characteristics of these respondents are given in Table 6.

\begin{tabular}{|clll|}
\hline S/No & Organization & Position Held & Working Experience (in yrs.) \\
\hline & & & \\
1 & Client & Project Director & 18 \\
2 & Contractor & Project Manager & 17 \\
3 & Client & Resident Engineer & 20 \\
4 & Consultant & Project Manager & 22 \\
5 & Contractor & Senior Project Manager & 23 \\
6 & Contractor & Project Engineer & 19 \\
7 & Consultant & Principal Partner & 27 \\
8 & Client & Senior Project Director & 17 \\
9 & Client & Senior Assistant Director & 15 \\
10 & Contractor & Deputy Managing Director & 26 \\
11 & Contractor & Managing Director & 28 \\
12 & Client & Technical Assistant Director & 24 \\
13 & Consultant & Resident Engineer & 15 \\
14 & Contractor & Project Director & 27 \\
15 & Consultant & Project Manager & 17 \\
16 & Contractor & Site Engineer & 12 \\
17 & Client & Resident Engineer & 13 \\
18. & Contractor & Site Engineer & 12 \\
19 & Consultant & Resident Engineer & 13 \\
20 & Contractor & Site Engineer & 14 \\
& & & \\
\hline & & & \\
\hline
\end{tabular}

Table 6 - Characteristic of Respondents who participated in the Qualitative Survey 
Their views and suggestions from the wealth of experience accumulated over the years on the most suitable ways of mitigating the causes of delays and cost overruns in construction projects helped in developing the strategies listed in Table 7. These strategies, when implemented, could guarantee optimal time and cost performance that would lead to the delivery of successful projects. The strategies are proactive for the planning phase and reactive for the execution phase. However, some of the strategies may find application at both the planning and execution phases of the project because of their fluid nature.

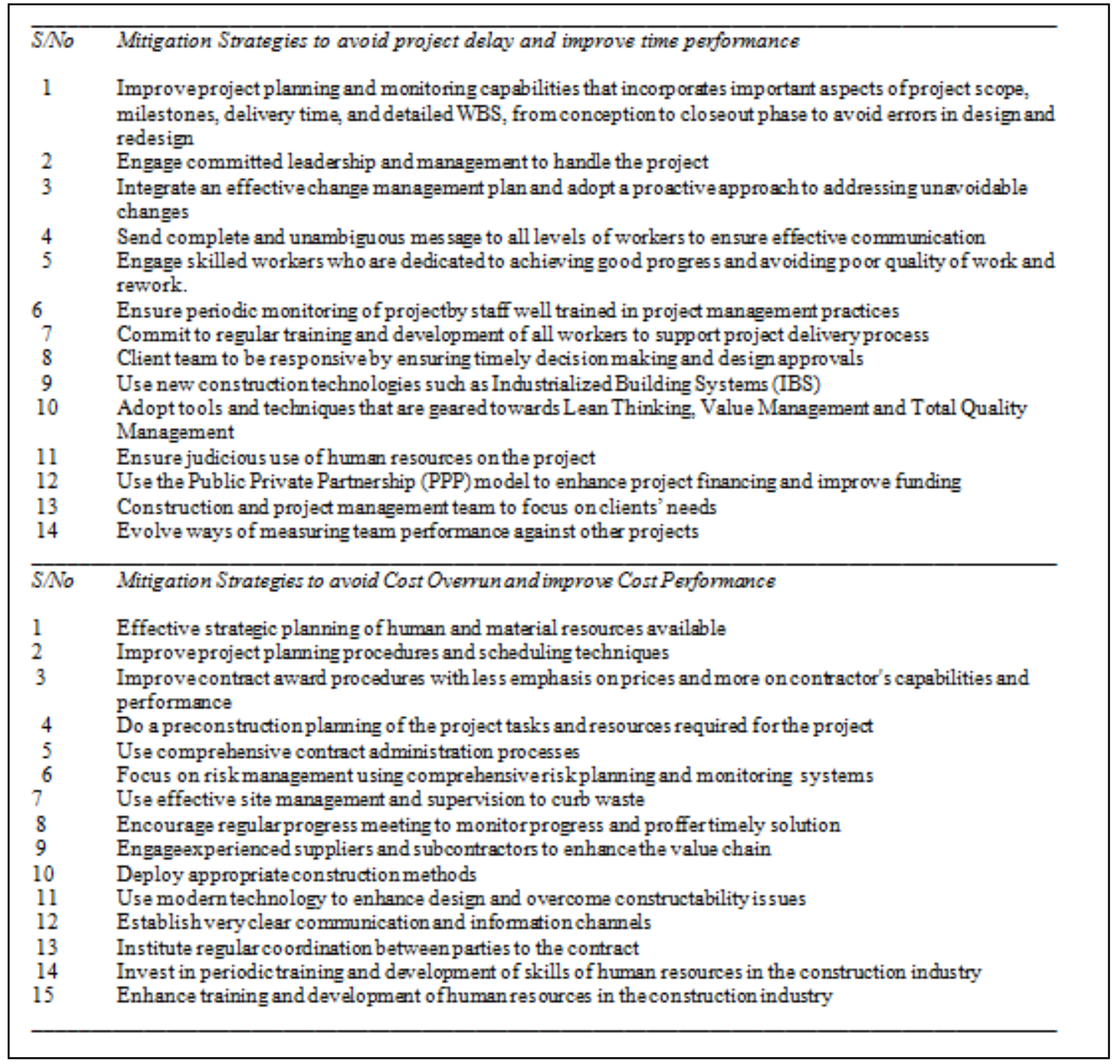

Table 7: Mitigation Strategies to Avoid Time and Cost Overrun and Improve Project Performance

\section{Conclusion and Recommendations}

Poor time and cost performance has remained the bane of construction projects today. Bearing that in mind, this study set out not only to investigate the causes of delays and cost overruns on construction projects, but to also come up with strategies that could be used to mitigate against their occurrence on construction projects. The study has established that delays and cost overruns are still prevalent and rampant on construction projects in Nigeria. They both impede successful project completion. Of the causes of project delays, the most significant were: design and scope change, inadequate availability of skilled resources, and ineffective procurement planning. And most significant causes of cost overruns were: escalation of prices of construction materials, escalation of labor costs/ineffective use of labor, and scope changes.

The study has developed 14 strategies for mitigating delays and 15 strategies for mitigating cost overruns occurring in construction projects, which when applied, will improve time and cost performance and pave way for successful projects that meet both time and cost objectives. The strategies fall into two broad categories; proactive and reactive. The strategies for the planning phase of the project are proactive, while the ones for the execution phase are reactive. The strategies will help practitioners adopt suitable guidelines for avoiding overruns.

The study recommends that organizations commit to regular training and development of their human resources to be sure they are up to the challenge of modern project planning and construction technologies. Comprehensive risk planning and monitoring systems should be adopted for managing construction projects. Modern technologies should be used to enhance designs and overcome constructability issues that often lead to redesign and delays. 


\section{References}

i. Adam, A., Josephson, P. \& Lindahl, G. (2014) 'Implications of cost overruns and time delays on major public construction projects,' Proceedings of the 19th International Symposium on the Advancement of Construction Management and Real Estate, 7-9 Nov 2014, Chongqing

ii. Chan, A.P.C., Scott, D. \& Chan, A.P.L. (2004) 'Factors affecting the success of a construction project', Journal of Construction Engineering and Management, (2004), 130, 153-155.

iii. Flyvbjerg, B., Skamris-Holm, M. K. \& Buhl, S. L. (2003) 'How common and how large are cost overruns in transport infrastructure projects?' Transport Reviews,23 (1), 71-88.

iv. Flyvbjerg, B., Bruzelius, N. \& Rothengatter, W. (2003) 'Megaprojects and risk: an anatomy of ambition,' Cambridge: Cambridge University Press.

v. Flyvbjerg, B. (2005) 'Policy and planning for large infrastructure projects: problems, causes, cures.' World Bank Policy Research Working Paper, WPS3781, World Bank, Washington DC.

vi. Kaming, P.F., Olomolaiye, P.O., Holt, G.D. \& Harris, F.C. (1997) 'Factors influencing construction time and cost overruns on high-rise projects in Indonesia', Construction Management and Economics, 15 (1), pp. 83-94.

vii. KPMG-PMI (2012) Study on project schedule and cost overruns [online]. Retrieved from: https://www.kpmg.com/IN/en/IssuesAndInsights/ArticlesPublications/Documents/PMI-KPMG-2013.pdf (Accessed: 17/2/16).

viii. Morris, P.W.G. \& Hough, G.H. (1987) The anatomy of major projects: a study of the reality of project management. Chichester; New York: Wiley.

\section{Appendix}

\section{Critical Values for Spearman's Rank Correlation Coefficient}

Use this table to determine the significance of your result for this test. For example, if you had 20 pairs of data and a value of 0.53 , then there would be a probability of between 0.01 and 0.005 that it had occurred by chance. In other words, you might expect to get this result occurring by chance once every 100-200 times. This, therefore indicates a very significant correlation between the two sets of data.

\begin{tabular}{|c|c|c|c|c|c|}
\hline $\begin{array}{c}\mathbf{N} \\
\text { (number of } \\
\text { pairs) }\end{array}$ & 0.1 & 0.05 & 0.025 & 0.01 & 0.005 \\
\hline 4 & 1.0000 & 1.0000 & 1.0000 & 1.0000 & 1.0000 \\
\hline 5 & 0.7000 & 0.9000 & 0.9000 & 1.0000 & 1.0000 \\
\hline 6 & 0.6571 & 0.7714 & 0.8286 & 0.9429 & 0.9429 \\
\hline 7 & 0.5714 & 0.6786 & 0.7857 & 0.8571 & 0.8929 \\
\hline 8 & 0.5476 & 0.6429 & 0.7381 & 0.8095 & 0.8571 \\
\hline 9 & 0.4833 & 0.6000 & 0.6833 & 0.7667 & 0.8167 \\
\hline 10 & 0.4424 & 0.5636 & 0.6485 & 0.7333 & 0.7818 \\
\hline 11 & 0.4182 & 0.5273 & 0.6091 & 0.7000 & 0.7545 \\
\hline 12 & 0.3986 & 0.5035 & 0.5874 & 0.6713 & 0.7273 \\
\hline 13 & 0.3791 & 0.4780 & 0.5604 & 0.6484 & 0.6978 \\
\hline 14 & 0.3670 & 0.4593 & 0.5385 & 0.6220 & 0.6747 \\
\hline 15 & 0.3500 & 0.4429 & 0.5179 & 0.6000 & 0.6536 \\
\hline 16 & 0.3382 & 0.4265 & 0.5029 & 0.5824 & 0.6324 \\
\hline 17 & 0.3271 & 0.4124 & 0.4821 & 0.5577 & 0.6055 \\
\hline 18 & 0.3170 & 0.4000 & 0.4683 & 0.5425 & 0.5897 \\
\hline 19 & 0.3077 & 0.3887 & 0.4555 & 0.5285 & 0.5751 \\
\hline 20 & 0.2992 & 0.3783 & 0.4438 & 0.5155 & 0.5614 \\
\hline 21 & 0.2914 & 0.3687 & 0.4329 & 0.5034 & 0.5487 \\
\hline 22 & 0.2841 & 0.3598 & 0.4227 & 0.4921 & 0.5368 \\
\hline 23 & 0.2774 & 0.3515 & 0.4132 & 0.4815 & 0.5256 \\
\hline 24 & 0.2711 & 0.3438 & 0.4044 & 0.4716 & 0.5151 \\
\hline 25 & 0.2653 & 0.3365 & 0.3961 & 0.4622 & 0.5052 \\
\hline 26 & 0.2598 & 0.3297 & 0.3882 & 0.4534 & 0.4958 \\
\hline 27 & 0.2546 & 0.3233 & 0.3809 & 0.4451 & 0.4869 \\
\hline 28 & 0.2497 & 0.3172 & 0.3739 & 0.4372 & 0.4785 \\
\hline 29 & 0.2451 & 0.3115 & 0.3673 & 0.4297 & 0.4705 \\
\hline 30 & 0.2407 & 0.3061 & 0.3610 & 0.4226 & 0.4629 \\
\hline
\end{tabular}

